Dossiê Especial: Experiências do PIBID na formação inicial e continuada de professores de

línguas estrangeiras

HIBARINO \& NODARI (orgs)

Revista X, vol.1, 2015

\title{
ADAPTAR PARA INCLUIR: CONFLITOS E DESAFIOS DO ENSINO DE JOVENS E ADULTOS NO PROJETO PIBID - INGLÊS UFPR
}

Adapting to include: the conflicts and challenges involved in the teaching of young and adult learners in the PIBID - Inglês UFPR project

Thais Rodrigues CONS $^{1}$

Resumo: O Ensino de Jovens e Adultos (EJA), mesmo que de extrema relevância e importância no contexto sócio histórico brasileiro, ainda se apresenta como um grande desafio para os educadores nas questões de adaptação dos alunos em sala de aula, de currículo e de orientações metodológicas. Considerando o desafio, este texto busca problematizar os conflitos ocorridos nas oficinas de ensino de língua inglesa promovidas pelo PIBID - Inglês - Programa Institucional de Bolsa de Iniciação à Docência na Universidade Federal do Paraná e discutir, com base na teoria do Letramento Crítico LC, até que ponto as Diretrizes Curriculares Nacionais e o Projeto Político Pedagógico da Escola dão suporte para os professores envolvidos com a educação de jovens e adultos. Com o aporte teórico mencionado e através do relato da experiência de adequação do projeto, conclui-se que a adaptação de alunos jovens e adultos é viável se considerarmos um currículo abrangente e a multiplicidade de identidades formadas no espaço escolar.

Palavras-chave: EJA, ensino de língua inglesa, PIBID, letramento crítico.

\begin{abstract}
The education of youth and adults, despite its relevance and importance in the Brazilian social-historical context, is still being presented as one major challenge for educators in matters of adaptation, curriculum and methodological guidelines. Considering the aforementioned challenge, this paper raises questions about conflicts that occurred in the workshops of English language promoted by PIBID - Inglês - UFPR in the schools and discusses, based on the theory of the critical literacy, the extent to which the National Curriculum Guidelines and the educational policy project of the school give support to the teachers involved with such groups of learners. With the theoretical assumptions mentioned and through the reports of the project revision experience, it is possible to conclude that the adaptation of the youth and adult learners is possible if a comprehensive curriculum and the multiplicity of the identities formed in the school environment are considered.
\end{abstract}

Keywords: EJA, English language teaching, PIBID, critical literacy.

\section{Contexto do PIBID - Inglês UFPR}

O presente texto tem como base a experiência dos bolsistas do PIBID - Programa Institucional de Bolsa de Iniciação à Docência - Projeto Inglês da Universidade Federal do

\footnotetext{
${ }^{1}$ Graduanda em Letras pela Universidade Federal do Paraná. thcns@gmail.com
} 


\section{Dossiê Especial: Experiências do PIBID na formação inicial e continuada de professores de línguas estrangeiras \\ HIBARINO \& NODARI (orgs) \\ Revista X, vol.1, 2015}

Paraná (UFPR). Tem como propósito problematizar as relações entre os licenciandos ${ }^{2}$ e os estudantes da escola pública, focando principalmente os alunos da Educação de Jovens e Adultos (EJA) e os impactos causados pelas oficinas PIBID em Inglês nas suas trajetórias educacionais.

Dentro do programa PIBID, que promove a integração entre Universidade, Graduandos de licenciaturas e Escola pública, nós, bolsistas, desenvolvemos ações para atender as necessidades locais. Uma destas ações aconteceu em um projeto denominado "Masterclass", realizado no Colégio Estadual Algacyr Munhoz Maeder, no Bairro Alto, cidade de Curitiba, Paraná. O projeto foi realizado com uma turma heterogênea em questões de idade, gênero e nível sócio econômico, e foi desenvolvido no período da noite entre os meses de agosto e novembro de 2013. Os bolsistas envolvidos com a preparação e execução do projeto eram um grupo de 4 pessoas, e a dinâmica da preparação das aulas contou com várias características peculiares que serão apresentadas e discutidas brevemente a seguir.

Uma das particularidades desta turma, sobre a qual este relato trata em especial, foi a grande participação dos alunos de EJA. Considerando que o período escolhido para a realização das oficinas foi o noturno, os adultos, maioria masculina e com idades variando de 18 a 35 anos, compareceram na maioria dos encontros - entre 10 a 15 deles. Por isso, o grande desafio foi adaptar nossas ideias iniciais ao público real da oficina, além de lidar com o distanciamento que muitos dos alunos mostravam em relação não só ao espaço escolar, mas também em relação à língua inglesa - que acabou causando algum estranhamento nos alunos, uma vez que a maioria deles não possuía, à época da realização da oficina, um contato prévio com este idioma ou um fácil acesso a ele fora da sala de aula.

A princípio, a experiência de "encarar" os alunos de EJA pareceu uma tarefa não só diferente das nossas vivências prévias na sala de aula, mas desafiadora em questões de planejamento, execução e até mesmo no convívio dos alunos adultos e dos bolsistas PIBID uma experiência que poderia gerar, e que de fato gerou, certos conflitos no espaço escolar. $\mathrm{O}$ desafio maior nas turmas de EJA, para os licenciandos, consistiu não só na falta da experiência prévia destes na sala de aula - afinal para alguns este foi o primeiro contato com o ambiente escolar na posição docente -, mas também a idade dos alunos, muitas vezes mais velhos, o que causou certo nervosismo e um sentimento de intimidação.

\footnotetext{
${ }^{2}$ Os participantes/bolsistas do PIBID - UFPR são chamados de licenciandos por serem alunos de licenciatura, ou pibidianos, por serem membros do projeto PIBID - Inglês.
} 
Dossiê Especial: Experiências do PIBID na formação inicial e continuada de professores de

línguas estrangeiras

HIBARINO \& NODARI (orgs)

Revista X, vol.1, 2015

A partir desta experiência e destes conflitos, é possível questionar o processo de ensino e aprendizagem de uma língua estrangeira numa turma de EJA, trabalhando dentro da perspectiva do Letramento Crítico (LC) e percebendo como as multiplicidades de sentidos no ambiente escolar enriquecem a convivência. Afinal, segundo a pesquisadora Clarissa Jordão, os conflitos

são entendidos no LC como aspectos produtivos do poder, como sendo oportunidades para a construção de conhecimento, de aprendizado e de transformação de procedimentos interpretativos e visões de mundo. [...] os conflitos resultantes da percepção de mais de uma concepção ou visão são possíveis e justificáveis e podem construir uma aprendizagem transformadora [...] (JORDÃO, 2013, p. 43).

Para a seguinte reflexão sobre as aulas de inglês no contexto da Educação de Jovens e Adultos (EJA), a parte inicial do texto apresentará as Diretrizes Curriculares para o ensino de EJA em conflito com o Projeto Político Pedagógico (PPP) do colégio estadual no qual o projeto em questão foi desenvolvido. Em seguida, serão relatados alguns aspectos práticos do desenvolvimento do projeto, assim como os conflitos que foram enfrentados pelos bolsistas e a adaptação necessária da oficina para ser relevante para o real público alvo. No terceiro momento, exemplificarei o trabalho feito nas oficinas por meio da apresentação de uma das atividades realizadas analisada sob a luz do LC e, por fim, traçarei as conclusões finais, medindo os efeitos da oficina nas trajetórias tanto dos bolsistas quanto dos alunos.

\section{A EJA e o PPP: conciliação possível?}

A Educação de Jovens e Adultos (EJA) é um grande segmento das escolas públicas brasileiras e merece atenção proporcional à sua importância. Aos educadores e professores que se propõem trabalhar com esses alunos, impõe-se a necessidade de entender a complexidade de uma sala de aula como a da EJA: diversa em termos de conhecimentos, motivações e conforto do estudante quando inserido no ambiente escolar. Muitas vezes há conflitos dentro da EJA devido às diferenças de idade, tanto pela presença de jovens adultos nas aulas quanto por adultos mais velhos, e também pelo conflito de idade entre os professores e os alunos.

No sentido de orientar as instituições educacionais e os professores de educação básica que trabalham com a EJA, existe a Normativa, elaborada e publicada pelo governo do estado 


\section{Dossiê Especial: Experiências do PIBID na formação inicial e continuada de professores de línguas estrangeiras \\ HIBARINO \& NODARI (orgs) \\ Revista X, vol.1, 2015}

do Paraná em 2006, com as Diretrizes Curriculares para o EJA. Segundo o pesquisador Wagner Andriola, as regiões Sul e Sudeste do país são as que mais têm alunos de EJA que concluem os estudos (ANDRIOLA, 2014, p. 1), e neste contexto, as Diretrizes se tornam ainda mais relevantes. $\mathrm{O}$ documento fornece um breve histórico da educação com foco em jovens e adultos no país, e depois traça o perfil dos educandos e os eixos orientadores do currículo, além de orientações metodológicas. O documento é, portanto, uma referência valiosa para esse setor.

O trabalho com a EJA vai além do perfil dos estudantes. Apesar de encararmos sempre o educando como um sujeito com visões e bagagens próprias, tanto na educação básica de ensino fundamental e médio, é preciso dar especial atenção para essa cultura quando se trata da EJA justamente pelas diferentes idades e pelos diferentes motivos que levam o aluno a retornar à escola, pela sua trajetória e os seus conhecimentos, especialmente considerando a função social da educação neste contexto:

O universo da EJA contempla diferentes culturas que devem ser priorizadas na construção das diretrizes educacionais. Conforme Soares (1986), o educando passa a ser visto como sujeito sócio-histórico-cultural, com conhecimentos e experiências acumuladas. Cada sujeito possui um tempo próprio de formação, apropriando-se de saberes locais e universais, a partir de uma perspectiva de ressignificação da concepção de mundo e de si mesmo. Tendo em vista a diversidade desses educandos, com situações socialmente diferenciadas, é preciso que a Educação de Jovens e Adultos proporcione seu atendimento por meio de outras formas de socialização dos conhecimentos e culturas. (DIRETRIZES, 2006, p. 27)

Ao definir a EJA em um contexto específico - Projeto Político-Pedagógico (PPP) -, no entanto, as orientações documentais ficam mais precárias. O PPP da escola em questão, documento de construção coletiva e local que visa fazer um diagnóstico da realidade da escola e propor ações e metas, menciona a EJA apenas na "identificação", não problematizando em momento nenhum o deslocamento dos jovens e adultos em relação ao ambiente escolar e nem as dificuldades/particularidades dessa modalidade de educação básica. Também, ao traçar ações pedagógicas para serem adotadas na escola, o PPP focaliza apenas e principalmente as séries iniciais e finais dos ensinos fundamental e médio.

Assim, o leitor que analisar o PPP do Colégio Algacyr Munhoz Maeder em busca de ações e problematizações que considerem a Educação de Jovens e Adultos, dificilmente encontrará uma proposta satisfatória. Este recorte do PPP, ou seja, as questões nas quais o 
Dossiê Especial: Experiências do PIBID na formação inicial e continuada de professores de

línguas estrangeiras

HIBARINO \& NODARI (orgs)

Revista X, vol.1, 2015

PPP se concentra e que excluem a EJA, pode ser interpretado como uma atribuição, à EJA, de importância menor na realidade da escola em questão.

\section{Perspectivas e adaptações da proposta}

Ao relatar as perspectivas e as modificações feitas na oficina "Masterclass", é necessário nos lembrarmos do contexto da experiência em questão. A proposta "Masterclass", dentro do contex to PIBID - Inglês UFPR, surgiu com a ideia de unir demandas e necessidades dos alunos da escola pública por um conhecimento mais específico com os pressupostos do LC e a discussão de questões culturais relevantes no espaço escolar. O principal conflito gerado quando a proposta foi posta em prática foi o fato de que, visando suprir demandas identificadas por nós em observações anteriores, focamos a preparação das nossas atividades para um público majoritariamente adolescente, entre 16-18 anos, idade em que os alunos estariam interessados em ingressar na universidade. $O$ fio condutor das ações do "Masterclass" era aliar debates e a desconstrução de sentidos com um conhecimento de língua um pouco mais refinado, tendo como principal objetivo a ressignificação de realidades e crenças dentro da sala de aula:

O reconhecimento da multimodalidade que nos cerca, acompanhado do trabalho escolar com a variedade de formas de comunicação utilizadas pelas sociedades hoje e seu inter-relacionamento, é um campo bastante rico para se tomar consciência desta miríade de maneiras de construir sentidos de que dispomos no mundo contemporâneo. O letramento, conceito mais abrangente do que "alfabetização" e capaz de englobar a variedade de linguagens do mundo atual, chama nossa atenção para diferentes formas de construção e compartilhamento de sentidos possíveis. (JORDÃO, 2007, p. $6)$.

Buscamos também enriquecer o vocabulário dos alunos, vocabulário este relacionado a situações diárias e também fornecendo subsídios para que pudessem compreender e interpretar textos simples em língua inglesa. A proposta, com duração de 04 meses (agosto novembro de 2013), se deu por meio de encontros com $2 \mathrm{~h}$ de duração, uma vez por semana, no período da noite. A sala multimídia do colégio, um espaço mais amplo onde era possível organizar os alunos em equipes ou dispor as cadeiras em círculo para discussões, foi utilizada para os encontros. Além do espaço, a sala também foi importante pela presença de recursos 
Dossiê Especial: Experiências do PIBID na formação inicial e continuada de professores de

línguas estrangeiras

HIBARINO \& NODARI (orgs)

Revista X, vol.1, 2015

como projetor e som, já que a maior parte das atividades propostas envolveu imagens, som e vídeos.

No entanto, durante a execução da proposta nos deparamos com uma situação que nos obrigou a reformular o formato e o foco das aulas. Foi esperado pelo grupo de bolsistas que a maior parte dos alunos participantes seria composta por alunos de ensino médio, principalmente do terceiro ano. Pelo fato de os encontros acontecerem à noite, era facultativo para os estudantes do ensino médio do período da manhã - então poucos compareciam. Os estudantes do ensino médio noturno não puderam frequentar as aulas por terem outras matérias no período em que realizávamos a proposta. Portanto, a maioria dos alunos que compareciam eram alunos do EJA que tinham aulas de inglês naquele horário: a turma da professora supervisora do PIBID, e de um segundo professor de inglês que trabalhava no colégio com turmas de EJA. Este professor abraçou a proposta e achou proveitoso unir as turmas.

À medida que as aulas foram se desenvolvendo, ficou claro para os bolsistas que abordar temáticas da adolescência e manter o foco em questões de vestibular não seria adequado naquele contexto: mais da metade dos 10 a 15 alunos da EJA que frequentavam as aulas estavam ali para terminar os estudos e continuar em seus empregos - ficou claro que a maioria dos alunos do EJA não tinha como objetivo prestar vestibular. Nesse contexto é interessante pensar o que ocorreu na prática em uma das aulas iniciais, o que será relatado com detalhes na terceira parte deste texto.

Os bolsistas foram orientados pela professora supervisora a adotar uma nova postura em relação aos alunos do EJA e não ter altas expectativas em relação à interação desse grupo de alunos, principalmente em termos de vocabulário e atividades mais ligadas com a língua inglesa. Afinal, muitos deles estavam distantes do espaço escolar e se sentiam intimidados e com medo de errar em público, ainda mais por se tratar de uma aula em outra língua.

As crenças sobre ensino e aprendizagem de inglês na escola pública podem ser, por vezes, bem limitadoras. Sobre isso, a pesquisadora Ana Maria Barcelos afirma:

Conforme apontado por Barcelos (2008), em sua revisão de alguns estudos sobre crenças de professores defendidos em programas de pós-graduação no Brasil, constatou-se que a maioria dos participantes desses estudos possui a crença de que não é possível aprender inglês em Escola Pública e de que o curso de idiomas é o lugar par excelence para se aprender essa língua. Barcelos (em andamento) sugere que a Escola Pública e o curso de idiomas são vistos como lugares dicotômicos na sociedade brasileira e no sistema de crença dos alunos. (BARCELOS, 2011, p. 149). 


\section{Dossiê Especial: Experiências do PIBID na formação inicial e continuada de professores de línguas estrangeiras \\ HIBARINO \& NODARI (orgs) \\ Revista X, vol.1, 2015}

Utilizamos, então, para nos aproximarmos desses alunos, uma abordagem próxima da conversa oral, procurando sempre apelar para a perspectiva que dialogava com assuntos que afetavam diretamente a realidade dos alunos. Sempre utilizando atividades, textos, músicas e trechos de vídeos em inglês, também introduzimos debates sobre as diferenças culturais nas datas comemorativas. Por exemplo, se no Brasil datas como Halloween, Natal, Dia dos namorados, entre outras, são comemoradas da mesma forma que nos países de língua inglesa. Assim, foi possível entrar em questões pessoais para os alunos, das quais surgiam relatos bastante reveladores das suas realidades. Além disso, discutimos questões polêmicas a respeito do mercado de trabalho como se a inserção da mulher era realmente igualitária ou se era mais importante se realizar uma tarefa que traz mais prazer ou recompensa monetária.

Com o passar das aulas, notamos o gradativo aumento na participação e no engajamento dos alunos nas atividades. Poucos alunos faltavam, a maioria deles demonstrava achar o curso relevante, além de que era perceptível, tanto para os bolsistas quanto para os alunos da EJA, que o ambiente em sala de aula era descontraído, aberto para suas opiniões e percepções de mundo. $\mathrm{O}$ ápice da participação dos alunos se deu em uma das últimas aulas do projeto, em que debatemos diferentes maneiras de lazer no Brasil e nos países estrangeiros, pela perspectiva da vida noturna e dos relacionamentos. Nessa aula pudemos realmente ter o retorno dos alunos tanto no sentido de participação e contribuição da realidade deles quanto na percepção deles sobre as diferenças culturais. Esta experiência será relatada com mais detalhes na sessão a seguir.

\section{Problemática na prática: contrastando atividades da proposta "Masterclass"}

Para exemplificar como a adaptação da proposta ocorreu principalmente no sentido explorado anteriormente sobre o conflito entre o que esperávamos e o que realmente aconteceu - uma preparação que foi feita mais voltada para questões de inglês e vestibular e que acabou tendo que ser adaptada para a real necessidade dos alunos EJA -, irei relatar duas experiências. Considero significativo o contraste da primeira atividade que aplicamos durante a proposta com uma das últimas aplicada ao final dos quatro meses. Pudemos perceber diferenças expressivas não só em termos de conteúdo, mas também na abordagem e na intensidade da participação dos alunos. 


\section{Dossiê Especial: Experiências do PIBID na formação inicial e continuada de professores de línguas estrangeiras \\ HIBARINO \& NODARI (orgs) \\ Revista X, vol.1, 2015}

A primeira atividade proposta já no primeiro encontro foi pensada com foco no LC, mas também visando uma familiarização dos alunos com modelos de questões consagrados por provas de vestibular. Por isso, escolhemos as questões da VUNESP (vide Anexo I). Essas questões vinham baseadas em dois anúncios adaptados. Além das questões gramaticais que exigiam conhecimento de classe de palavras na língua inglesa, as questões traziam ${ }^{3}$ triggers para discussões interessantes, como por exemplo, sustentabilidade, uso sustentável de recursos como água e eletricidade e a possibilidade do uso do gênero publicitário para, além da própria função apelativa, provocar uma reflexão do alvo para as problemáticas ambientais. Seguindo os preceitos do LC e lembrando que “[...] precisamos localizar os problemas, ou seja, construí-los e representá-los, formulando questionamentos conceituais críticos (buscando entender os pressupostos e implicações da nossa realidade) [...]" (JORDÃO, 2013, p. 43-44), a justificativa para nossa escolha foi a possibilidade de os alunos conseguirem problematizar a ideia de anúncio/gênero publicitário, e também relativizar o discurso do "sustentável", pensando em seus próprios contextos diários e discutindo quais significados tais discursos teriam para eles.

Esta atividade acabou sendo realizada nos 40 minutos finais da aula, após a apresentação inicial dos bolsistas PIBID e dos alunos que estavam ali presentes. Não foi possível identificar de imediato as razões pelas quais os alunos não participaram muito, mas entre as alternativas consideramos o cansaço - afinal propusemos o trabalho às $20 \mathrm{~h} 30 \mathrm{da}$ noite - , o desinteresse, o estranhamento causado pela interpretação do gênero anúncio ou o receio de lidar com uma prova de vestibular. O resultado foi uma quebra de expectativa. Esta aula havia sido planejada para ser interativa e se tornou rapidamente, devido à falta de interação efetiva dos alunos, uma aula expositiva - assim, não muito produtiva. Segue impressão de um dos pibidianos retirada do registro semanal (diário de bordo) ${ }^{4}$ sobre a situação:

A diferença entre o que nós esperávamos e o que realmente aconteceu foi notável, afinal não tínhamos preparado a aula para uma maioria do noturno/EJA, e sim para o ensino médio que parecia bem empolgado com a ideia da Masterclass, mas acabou não aparecendo. Quem sabe na próxima

\footnotetext{
${ }^{3}$ Trigger, ou acionador de gatilho, nesse contexto é usado para fazer referência a assuntos que provocam ou dão início a uma discussão em sala de aula.

4 "Diário de bordo" é o nome dado aos registros feitos regularmente pelos integrantes do PIBID subprojeto Inglês da UFPR em uma página do google sites. Toda vez que alguma atividade relacionada ao PIBID era realizada, tanto na escola quanto na universidade, os bolsistas faziam registros com descrições e impressões para serem analisados posteriormente. A página é de acesso restrito aos membros do subprojeto.
} 


\section{Dossiê Especial: Experiências do PIBID na formação inicial e continuada de professores de línguas estrangeiras \\ HIBARINO \& NODARI (orgs) \\ Revista X, vol.1, 2015}

semana a coisa melhore um pouco e mais alguns alunos apareçam. Mesmo assim, acho legal já considerarmos a participação em massa dos alunos mais velhos e fazermos alguns ajustes na programação. Todos podemos concordar, acho, que a atividade com as questões de vestibular foi um pouco pesada (mas achei legal). O nível de interesse dos alunos foi razoável para um trabalho pesado (e inicial) com a língua inglesa, mas não sei se atividades como essa irão funcionar sempre. Precisamos verificar quem vai aparecer nas próximas semanas, se mais EJA ou mais alunos do terceiro ano. Apesar de todas as dificuldades iniciais, acredito que a gente vá se ajustar e o projeto vá ser bem produtivo. Pela minha percepção, temos ali vários alunos que sabem bastante de inglês e que podem ser ainda mais ajudados. (Pibidiano A, 2013).

Segundo a percepção registrada no diário, logo no primeiro encontro foi possível identificar a presença de conflito entre a versão "idealizada" da proposta e a versão posta em prática. Procuramos orientações da professora supervisora e, como relatado na sessão anterior, tentamos usar temas que ainda servissem para a desconstrução de conceitos e para o lançamento de um olhar crítico, mas que fossem de interesse real dos educandos. As Diretrizes determinam que "[a] EJA deve ter uma estrutura flexível e ser capaz de contemplar inovações que tenham conteúdos significativos" (DIRETRIZES, 2006, p. 28) e precisávamos buscar essa adequação, para que o aprendizado fosse mais inclusivo e tangível para os alunos.

Na minha percepção, não foi uma tarefa fácil chegar nesse nível de adequação; por mais que possuíssemos suporte de nossas professoras supervisoras e da coordenadora do projeto PIBID. Atingir um patamar de real interesse dos alunos estando ainda em processo de formação docente inicial foi uma dificuldade real percebida pela maioria dos bolsistas. Por vezes, acabamos tentando ser "amigos" dos jovens adultos que participavam, achando que uma proximidade maior ajudaria no aprendizado deles, e fomos orientados pela supervisora que tal atitude não surtiria efeito positivo. Dentro do grupo, alguns bolsistas ouviram o "conselho" da supervisora, que foi motivado por experiências prévias de alunos da escola pública que, principalmente pelo contato via redes sociais como o Facebook, tiveram comportamentos inadequados para a relação professor-aluno, como investigar detalhes de sua vida pessoal.

Nas semanas que se seguiram, apesar da dificuldade, conseguimos realizar trabalhos com vocabulário básico na oficina que acrescentaram ao conhecimento e ao dia-a-dia dos alunos, nos aproximando cada vez mais dos "conteúdos significativos" aos quais as Diretrizes se referem. 


\section{Dossiê Especial: Experiências do PIBID na formação inicial e continuada de professores de línguas estrangeiras \\ HIBARINO \& NODARI (orgs) \\ Revista X, vol.1, 2015}

A segunda atividade a ser relatada e uma das experiências mais marcantes de todo o projeto, tanto para os educandos do EJA quanto para os pibidianos, foi o trabalho com vocabulário de situações de lazer para os participantes dos encontros. Foi possível perceber o impacto deste dia ao ouvir o feedback dos alunos do EJA ao final da proposta e também ao ler as impressões dos licenciandos sobre a atividade no diário de bordo.

Seguindo uma direção totalmente diferente do trabalho com as questões da VUNESP, nesse dia propusemos uma discussão oral com os alunos utilizando uma apresentação em powerpoint, de nossa autoria, que trazia imagens e algumas expressões em inglês. A atividade tomou a aula toda e é seguro afirmar que teria sido difícil prever os rumos que esta tomou no sentido de discussões e desconstruções de sentido, além de termos nos aprofundado nas questões multiculturais e nas diferenças de cultura.

Abordamos, nessa atividade à qual demos o nome de "clubbing and being social", aspectos de lazer e vida noturna, e solicitamos exemplos de locais que os alunos frequentavam, o que comiam e bebiam, além de seus relacionamentos. Apresentamos expressões e gírias na língua inglesa, e ao fazer isso, discutimos diferenças culturais entre países estrangeiros e o Brasil, também comparando a realidade dos alunos e diversos estereótipos em termos de convívio social e relações.

Um dos slides da apresentação utilizada (vide Anexo II) com o objetivo de ilustrar o tema apresentava expressões de gíria do inglês e a "nova escrita" que surge com as mensagens instantâneas e as redes sociais. Acredito que a nossa iniciativa se pauta nos preceitos do LC, pois estávamos trabalhando com informação e construção de saberes dentro do espaço escolar de acordo com o que afirma Roxane Rojo:

Podemos dizer que, por efeito da globalização, o mundo mudou muito nas duas últimas décadas. Em termos de exigências de novos letramentos, é especialmente importante destacar as mudanças relativas aos meios de comunicação e à circulação da informação. (ROJO, 2008, p. 3).

Além de questões linguísticas e expressões, tratar de relacionamentos nos rendeu momentos polêmicos de discussão, e assuntos polêmicos, tais como a cultura do machismo, o homossexualidade e o abuso sexual foram abordados. Segue o feedback da professora supervisora sobre a atividade, registrado em diário de bordo:

A facilidade que os bolsistas têm pra lidar com assuntos polêmicos é impressionante! ... e digo mais: a maioria dos professores correm 


\section{Dossiê Especial: Experiências do PIBID na formação inicial e continuada de professores de línguas estrangeiras \\ HIBARINO \& NODARI (orgs) \\ Revista X, vol.1, 2015}

quilômetros desse tipo de temática! Vocês utilizaram um vocabulário apropriado, a postura diante dos questionamentos foi elegante, abordaram a questão do estupro e do uso às vezes indevido das redes sociais com muito critério e responsabilidade! Congratulations!!! (...) (Supervisora A, 2013).

Por meio da língua inglesa, que acaba sendo ferramenta para trocas culturais e para a globalização, obtivemos subsídios para discussões interculturais, tendo como base o conceito de língua franca; na compreensão que Marko Modiano apresenta deste termo: a de ser "uma língua de ampla comunicação[...]"'(MODIANO, 2001, p. 344; tradução livre) $)^{5}$. Acredito que a desconstrução de estereótipos e a comparação das relações dos alunos, aliados à questão da língua franca, foram exemplos de aplicação prática de pressupostos do LC em sala de aula. A oposição entre as diferentes visões e pontos de vista traz o esperado conflito produtivo de que o LC necessita, e traz a desconstrução das verdades únicas que muitas vezes imperam na sala de aula. Acredito que com essa atividade em especial nos aproximamos da "aprendizagem transformadora" (JORDÃO, 2013, p. 43) que esperávamos. Outra impressão de um bolsista, ainda extraída do diário de bordo, retrata o impacto da atividade:

Essa semana foi polêmica e falamos sobre bebida, balada e até questões sérias como estupro e relacionamentos. Como a professora supervisora disse, "aproveitem que aula como essa não vai ter nunca mais em lugar nenhum", e realmente, não vai. Foi bom para quebrarmos várias barreiras e conversar abertamente sobre expressões machistas, termos de relacionamentos e a questão do abuso sexual. Começo a ver que os alunos realmente estão se sentindo confortáveis com o nosso projeto e estão gostando. Os que não estão tão à vontade, pelo menos estão percebendo o esforço para fazer algo legal e levar para a sala de aula. Um exemplo é o José (pseudônimo), o aluno que possivelmente, segundo alguns professores, tem problema com drogas e não vai às aulas regularmente. Pois então, o José tem conseguido participar regularmente das nossas aulas de terça feira! Segundo a professora supervisora, ele não fica em nenhuma sala, e na nossa aula ele fica. Sentei ao lado dele hoje e ele falou algumas coisas que mereciam ir pro mural de pérolas, mas fiquei feliz que ele estava acompanhando o tema da aula e participando. Sobre os alunos que não estavam dando opinião com frequência, não sei se acabaram não participando tanto por timidez ou porque algumas coisas ali eram um pouco tabus, mas com certeza eles acabaram questionando algumas percepções. (Pibidiano B, 2013).

Assim, em uma das nossas últimas atividades, conseguimos um retorno bem diferente em relação à primeira atividade e nos aproximamos mais de um conteúdo significativo e de reflexões importantes, não só para a formação dos alunos EJA, mas também para a nossa própria trajetória como docentes em formação inicial.

\footnotetext{
${ }^{5}$ Language of wider communication, no original.
} 


\section{Dossiê Especial: Experiências do PIBID na formação inicial e continuada de professores de línguas estrangeiras \\ HIBARINO \& NODARI (orgs) \\ Revista X, vol.1, 2015}

\section{Considerações finais}

Quando penso na motivação inicial d proposta "Masterclass", acho curioso como uma ideia que tivemos acabou tomando rumos tão diferentes, mas mesmo assim foi tão benéfica para a nossa formação. Acredito que o PIBID dá ao licenciando bolsista de iniciação à docência uma oportunidade única de formação docente: além de criar meios para que trabalhemos com diferentes públicos e idades dentro da educação básica, o PIBID permite colocar nossas propostas, únicas e particulares, em prática, e depois nos dá também a reflexão sobre elas e sobre nossa própria trajetória. A partir deste estudo e de todas as observações, tive o privilégio de refletir sobre minhas ações no espaço escolar e, assim como me propus com o LC no projeto, desconstruí certos pressupostos que havia formado sobre a EJA.

O resultado de todo o trabalho, planejamento e adaptações feitas veio na despedida. Segue um dos feedbacks, de um aluno EJA, dado oralmente na última oficina que foi promovida:

Vocês ensinam diferente! Não é igual as outras matérias, que o professor só explica no quadro e a gente escuta. Vocês querem saber nossa opinião, e também as coisas que vocês falam são importantes pra nossa vida, são interessantes. (Aluno EJA A, 2013).

Apesar de ter sido um projeto pontual e relativamente curto, tivemos o retorno de que ele foi relevante e que os alunos aprenderam e adquiriram ferramentas de interpretação de texto e vocabulário. Mais do que conhecimento da língua inglesa, obtivemos resposta por parte dos alunos de que conseguimos fazê-los questionar algumas de suas ideias e conceitos. Colocamos em prática o LC, e tentamos abordar temáticas que se aproximassem do que seria relevante para a vida dos alunos. Ao possibilitar essa aprendizagem para eles, acabamos por aprender também, como docentes em formação inicial e como indivíduos.

\section{Agradecimento}

Agradeço à CAPES pela concessão da bolsa PIBID que possibilitou a realização desta pesquisa. 
Dossiê Especial: Experiências do PIBID na formação inicial e continuada de professores de línguas estrangeiras

HIBARINO \& NODARI (orgs)

Revista X, vol.1, 2015

\section{Referências}

ANDRIOLA, W. B. "Avaliação diagnóstica da Educação de Jovens e Adultos (EJA) no Brasil”. IN: Avaliação e Políticas Públicas em Educação. vol. 22 no.82 Rio de Janeiro jan./mar. 2014.

BARCELOS, A. M. F. "Lugares (im)possíveis de se aprender inglês no Brasil: crenças sobre aprendizagem de inglês em uma narrativa". IN: LIMA, Diógenes Cândido de [org.] Inglês em escolas públicas não funciona? Uma questão, múltiplos olhares. São Paulo: 2011, Pp. 147158.

JORDÃO, C. M. "Letramento Crítico em 2.500 palavras, mais ou menos..." . IN: ALBUQUERQUE, M. V. DE; BREDA, F.; EDMUNDO, E. S. G.; GOMES, H. O.; JORDÃO, C. M.; OLIVEIRA, L. C. DE; ROSA, A. da; \& TRINKEL, M. C.. O PIBIDUFPR nas Aulas de Inglês: divisor de águas e formador de marés. Curitiba: Pontes, 2013.

JORDÃO, Clarissa Menezes. "As lentes do discurso: Letramento e criticidade no mundo digital.” IN: Trab. Ling. Aplic., Campinas, 46(1): 19-29, Jan./Jun. 2007.

MODIANO, Marko. "Linguistic imperialism, cultural integrity and EIL". IN: ELT Journal. volume 55/4, 2001.

ROJO, Roxane. "O letramento escolar e os textos da divulgação científica - a apropriação dos gêneros de discurso na escola". IN: Linguagem em (Dis)curso - LemD, 8, n. 3, Pp. 581-612, Set./Dez. 2008.

PARANÁ, SEED. Diretrizes Curriculares de Língua Estrangeira para o Ensino Fundamental. Secretaria de Estado da Educação do Paraná, Superintendência da Educação, 2006.

PROJETO POLÍTICO PEDAGÓGICO: Colégio Estadual Algacyr Munhoz Maeder. 
Dossiê Especial: Experiências do PIBID na formação inicial e continuada de professores de línguas estrangeiras

HIBARINO \& NODARI (orgs)

Revista X, vol.1, 2015

ANEXO I

Fonte: Vestibular Vunesp $2013 \quad-\quad 1^{\text {a }}$ fase. Disponível em: <http://www.vunesp.com.br/VNSP1207/cg_V1.pdf >.

Instrução: Examine os anúncios para responder às questões de números 21 a 25.

ANÚNCIO 1

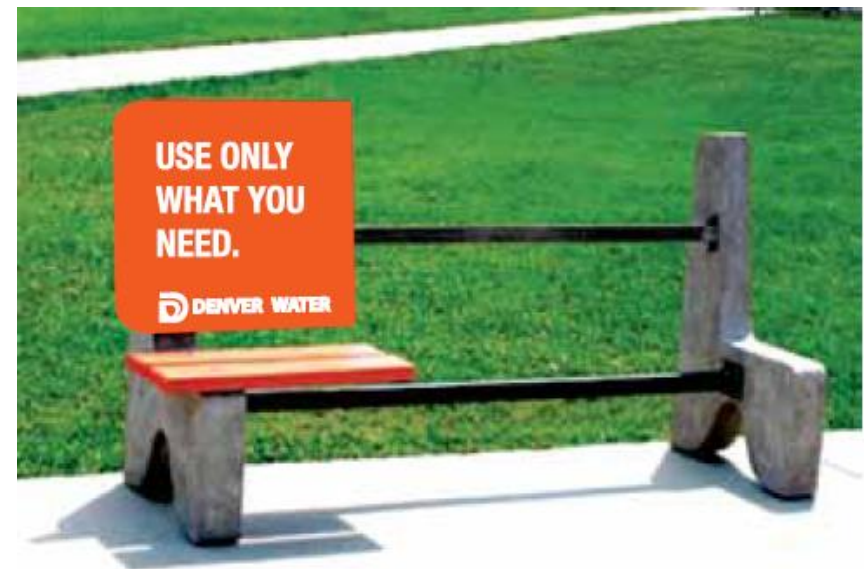

(www.hongkiat.com. Adaptado.)

\section{ANÚNCIO 2}

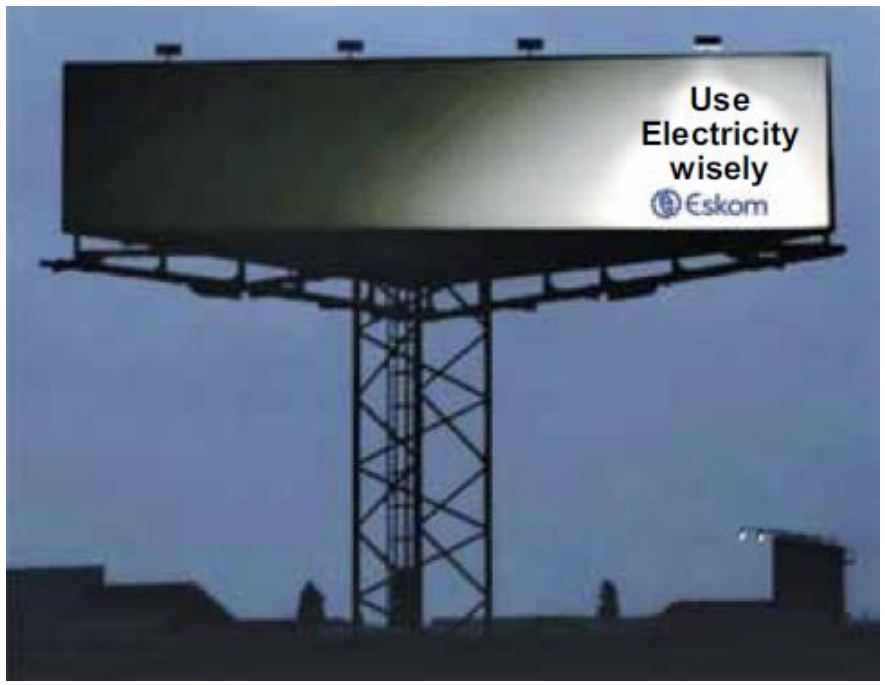

(www.crookedbrains.net. Adaptado.)

\section{Questão 21}

O anúncio 1 refere-se

(A) a uma campanha para economia do consumo de água.

(B) à divulgação de uma nova tinta para bancos de jardim.

(C) a uma campanha para embelezar a cidade de Denver.

(D) à divulgação de reformas nos jardins públicos em Denver.

(E) a uma campanha contra a destruição de patrimônio público.

\section{Questão 22}

$\mathrm{O}$ anúncio 2 refere-se

(A) a um incentivo para anúncios mais iluminados.

(B) a uma empresa de eletricidade chamada Wisely. 


\section{Dossiê Especial: Experiências do PIBID na formação inicial e continuada de professores de línguas estrangeiras \\ HIBARINO \& NODARI (orgs) \\ Revista X, vol.1, 2015}

(C) a um incentivo ao uso de lâmpadas fluorescentes.

(D) ao uso mais consciente de energia elétrica.

(E) à falta de iluminação suficiente em locais públicos.

\section{Questão 23}

Considerando-se o propósito do anúncio 2 , a oração que poderia fazer parte de um texto a ser incluído nesse anúncio é:
(A) Turn on the lights when a room is not being used.
(B) Turn on the heaters and boilers on summer days.
(C) Turn off the lights when there is nobody in a room.
(D) Turn on the tap before you take a bath or a shower.
(E) Turn off the tap while brushing your teeth or shaving.

\section{Questão 24}

Os dois anúncios têm em comum o fato de
(A) terem sido produzidos para empresas de pequeno porte.
(B) terem sido produzidos para duas empresas concorrentes.
(C) estimularem o uso de recursos alternativos.
(D) terem sido produzidos pela mesma agência de publicidade.
(E) estimularem ações embasadas na sustentabilidade.

\section{Questão 25}

Nos anúncios, as palavras use, you, need, electricity e wisely são exemplos, respectivamente, de
(A) substantivo, pronome, verbo, substantivo e advérbio.
(B) verbo, pronome, verbo, substantivo e advérbio.
(C) substantivo, adjetivo, verbo, substantivo e adjetivo.
(D) verbo, pronome, verbo, adjetivo e adjetivo.
(E) substantivo, pronome, substantivo, adjetivo e advérbio. 
Dossiê Especial: Experiências do PIBID na formação inicial e continuada de professores de línguas estrangeiras

HIBARINO \& NODARI (orgs)

Revista X, vol.1, 2015

ANEXO II

- IDK - I don't know

- ILY - I love you

- FYI - For your information

- BTW - By the way

- ASAP - As soon as possible

- BRB - Be right back

- OMG - Oh my god 